\title{
Outcome for hospitalized road trauma patients at a tertiary hospital in Kenya
}

\author{
Hassan Saidi \\ University of Nairobi \\ William Macharia \\ Aga Khan University, macharai.william@aku.edu \\ John Ating'a \\ University of Nairobi
}

Follow this and additional works at: https://ecommons.aku.edu/eastafrica_fhs_mc_paediatr_child_health

Part of the Pediatrics Commons

\section{Recommended Citation}

Saidi, H., Macharia, W., Ating'a, J. (2005). Outcome for hospitalized road trauma patients at a tertiary hospital in Kenya. European Journal of Trauma, 31(4), 401-406.

Available at: https://ecommons.aku.edu/eastafrica_fhs_mc_paediatr_child_health/17 


\title{
Outcome For Hospitalized Road Trauma Patients at a Tertiary Hospital in Kenya
}

\author{
Hassan S. Saidi', William M. Macharia², John E.O. Ating'a ${ }^{3}$
}

\begin{abstract}
Background: The developing world continues to experience a disproportionate burden of injury. About one half of injury deaths are due to motor vehicle collisions. Road traffic fatalities per 10,000 vehicles are ten to 20 times higher in Africa compared to Europe.

Patients and Methods: 233 patients were consecutively analyzed. Injury acuity was determined by calculating Injury Severity Scores (ISS) for each patient. Information on the care and treatment outcome was obtained from patient interviews, case notes and discharge summaries. Data analysis was performed using the SPSS version 10.0 statistical software.

Results: Injury accounted for $48.8 \%$ of all emergency hospitalizations into the surgical units. Injury due to traffic comprised a third (31\%) of trauma admissions. Injuries to the limbs were predominant (54\%). Acuity ranged from ISS 1 to 43 . The mean ISS was 8.78. Major injury (ISS > 15) constituted $13 \%$ of all the admissions. Operating room resources were utilized in $52 \%$ of the patients (major operations were performed in $12 \%$ of this group). The overall complication rate was $12.0 \%$. Although the overall mortality amounted to $6 \%$, mortality was $35.6 \%$ amongst those with major injury. It was also higher with associated head injury, pedestrian injury and weekend injury.

Conclusion: The overall trauma acuity was moderate injury. Mortality escalated to $35 \%$ for major injury. There is need to explore the factors contributing to this high mortality and a system of care that can optimize outcome.
\end{abstract}

\footnotetext{
${ }^{1}$ Departments of Anatomy \& Surgery, University of Nairobi, Nairobi, Kenya,

${ }^{2}$ Clinical Epidemiology Unit and Department of Pediatrics \& Childhealth, University of Nairobi, Nairobi, Kenya,

3 Department of Orthopedic Surgery, University of Nairobi, Nairobi, Kenya.
}

Received: June 25, 2004; revision accepted: March 1, 2005.

\author{
Key Words \\ Road traffic trauma - Outcome of care · Africa
}

Eur J Trauma 2005;31:401-6

DOI $10.1007 /$ s00068-005-1014-3

\section{Introduction}

Injury remains a significant global problem and a leading cause of death, disability and years of life lost in those 1-44 years of age [1,2]. About one half of injury deaths are attributable to road traffic collisions. The injuries and disability demand costly therapeutic and rehabilitative intervention. Road traffic fatalities per 10,000 vehicles are estimated to be ten to 20 times higher in Africa compared to Europe [3]. In Kenya, the road safety record is poor with $>60$ deaths/10,000 vehicles/ year [4]. This compares unfavorably with the 10, 5 and 4.5 deaths/10,000 vehicles/year in Japan, the USA and Britain.

In Europe, Canada and the USA, injury-associated mortality is declining due to improvements in motor vehicle designs, highway designs and strict enforcement of traffic laws [1]. Systematic care of the traumatized patient has led to a significant reduction in excess mortality due to injuries [5]. In the developing world, however, there continues to be a steady rise in the proportion and absolute number of deaths from motor vehicle collisions $[6,7]$ with an annual growth in number of vehicles and related accidents at $6 \%$ and $3 \%$, respectively. The annual growth in number of fatalities remains at $8 \%[8]$. 
Despite the prevailing situation, there is little research work on the extent and severity of injuries, including those due to traffic $[9,10]$.

This study was undertaken to determine the outcome associated with road crashes in patients admitted to the Kenyatta National Hospital (KNH) in Nairobi, Kenya, between February and April, 1999.

\section{Patients and Methods}

Site

This study was carried out at the $\mathrm{KNH}$, a 2,000-bed teaching and referral hospital that also serves as a general hospital for 3 million inhabitants of the city of Nairobi. The KNH does not have a separate trauma unit. The injured are received at the hospital's accident and emergency department, assessed and discharged home or admitted to the general wards or intensive care unit (ICU) as the attending doctors deem fit. A minority of the doctors have ATLS ${ }^{\circledR}$ (Advanced Trauma Life Support) certification. They have access to surgical consultations (residents in training and on-call specialty surgeons) on a 24-h basis.

\section{Study Population}

The study population comprised all consecutive road accident casualties admitted alive between February 1, 1999 through April 30, 1999. Patients who died at the casualty department and those with insufficient records were excluded.

\section{Design}

Longitudinal survey with limited follow-up. The patients were followed up till discharge from hospital or death.

\section{Recruitment}

After approval from the $\mathrm{KNH}$ ethical board, patients were prospectively identified and recruited from the registration desk at the hospital's accident and emergency department and followed to their different wards and the ICU.

\section{Data Collection}

Information was obtained from patient interviews, casualty cards, case notes, operation notes and discharge summaries. Information collected included demographics, road user injured, time and day of accident, Injury Severity Score (ISS), anatomic region affected, alcohol use, treatment modalities, and outcome. In the determi- nation of ISS, the six body regions considered included head/neck, face, thorax, abdomen/pelvis, extremity/pelvis, and skin (external). Injuries sustained in each of the regions were scored (Abbreviated Injury Scale [AIS]) on a scale of 1-6 (minor to critical). The ISS were computed from the sums of the squares of three highest AIS scores. Mild injuries were scored 1-8, moderate 9-15, severe $15-25$, and critical $>25$. Predesigned questionnaires were filled in and updated on a daily basis.

\section{Definitions}

Road traffic injury (RTI) was defined as injury involving motor vehicles, bicycles, motorcycles or pedestrians. Daytime injuries were those that occurred between 06:30 a.m. and 06:30 p.m. Weekend injuries were those occurring between Friday and Sunday. The principal ISS region was defined as the anatomic region with the highest AIS. The sum of the squares of the three highest AIS scores was the ISS [11]. Craniotomy, thoracotomy, laparotomy, reconstruction of complex injuries, open reduction and fixation of fractures, and operations lasting $>1 \mathrm{~h}$ were considered major operations. Minor operations encompassed surgical toilet of wounds, wound suture or closed reductions and plaster application/external splinting for fractures.

Outcome was regarded as satisfactory if the patient healed without complications, unsatisfactory if complications ensued but later recovered completely, and poor if the patient either died or developed permanent disability.

\section{Data Analysis}

Data were entered into a personal computer, then analyzed using the SPSS version 10.0 statistical software. The injury severity data was summarized using means \pm SD (standard deviation) and ranges. Univariate analyses were performed for outcome and severity variables using the $\chi^{2}$-test. Fisher's exact test was used for patient numbers $<5$. The level of significance was $p<0.05$.

\section{Results}

There were a total of 5,493 emergency hospital admissions during the study period. Out of these, 28.9\% (95\% confidence interval [CI], 27-30.2) were admitted to the different surgical wards. Of the surgical admissions, $48.8 \%$ were due to trauma. Admissions due to traffic injuries accounted for $31.0 \%$ of all trauma and $15.1 \%$ (CI, 13.2-18.5) of all surgical admissions. Hospitalizations due to RTI constituted $6.2 \%$ of all emergency hospitalizations. 
Table 1. Factors influencing injury severity following road trauma at Kenyatta National Hospital. ISS: Injury Severity Score.

\begin{tabular}{|c|c|c|c|c|}
\hline & & $\begin{array}{l}\text { ISS } \leq 15 \\
\text { (n) }\end{array}$ & $\begin{array}{l}\text { ISS > } 15 \\
\text { (n) }\end{array}$ & $\mathrm{p}$-value \\
\hline \multirow[t]{2}{*}{ Day of week } & Weekday & 97 & 13 & 0.591 \\
\hline & Weekend & 90 & 15 & \\
\hline \multirow[t]{2}{*}{ Time of day } & Day & 134 & 18 & 0.394 \\
\hline & Night & 46 & 9 & \\
\hline \multirow[t]{2}{*}{ Alcohol status } & Yes & 70 & 10 & 0.747 \\
\hline & No & 92 & 10 & \\
\hline \multirow[t]{2}{*}{ ISS region } & Head/neck & 43 & 16 & $<0.001$ \\
\hline & Other & 143 & 12 & \\
\hline \multirow[t]{2}{*}{ Road user } & Pedestrian & 116 & 20 & 0.428 \\
\hline & Other & 66 & 8 & \\
\hline
\end{tabular}

A total of 233 RTI casualties were studied. There were $200(85.8 \%)$ males with a male : female sex ratio of $6: 1$. The average age was 29.9 years (range, $5-81$ years). The peak age group was 20-29 years.

The ISS ranged from 1 to 43 . The mean ISS \pm SD for the population was $8.78+6.97 .43 \%$ of the patients sustained moderate injuries (ISS 9-15). The proportion that sustained severe (ISS 15-25) and critical injuries (ISS > 25) was $10.6 \%$ and $2.8 \%$, respectively (Table 1 ). Those with mild injuries (ISS 1-8) were 95 (43.6\%).

The most severe injuries were in the abdomen/visceral pelvis (ISS $14.0+14.3$ ). These were followed by the chest (ISS $12.33+7.5$ ) and head/neck (ISS $10.4+9.1$ ). The mean ISS for the most prevalent ISS region was 7.64 +3.6 . The scores recorded for the face and external injuries were $5.3+2$ and $1.9+2$, respectively (Figure 1). By ISS definition, $27.1 \%$ of head injuries, $26.6 \%$ of chest injuries and $60 \%$ of abdominal injuries were severe. By contrast, only $4.2 \%$ of skeletal injuries had ISS $>15$.

Most injuries (163 [72.4\%]) occurred during the day. The proportion of injuries presenting during the weekend was $50.2 \%$. The mean nighttime and daytime ISS were 9.38 and 8.32 , respectively $(\mathrm{p}=0.33)$. Acuities did not differ for weekend (mean ISS 9.16) and weekday (mean ISS 8.16) injuries ( $\mathrm{p}=0.31$ ).

Pedestrians comprised $64.5 \%$ of the injured population. There was no difference in severity between pedestrians (mean ISS 9.15) and vehicle occupants (mean ISS $8.22 ; \mathrm{p}=0.39)$.

$54 \%(\mathrm{n}=124)$ of the patients were admitted with injuries to the limbs. The percentages of patients with head/neck, face, chest, abdomen and external injuries were $29,1,8,3$, and 5 respectively.

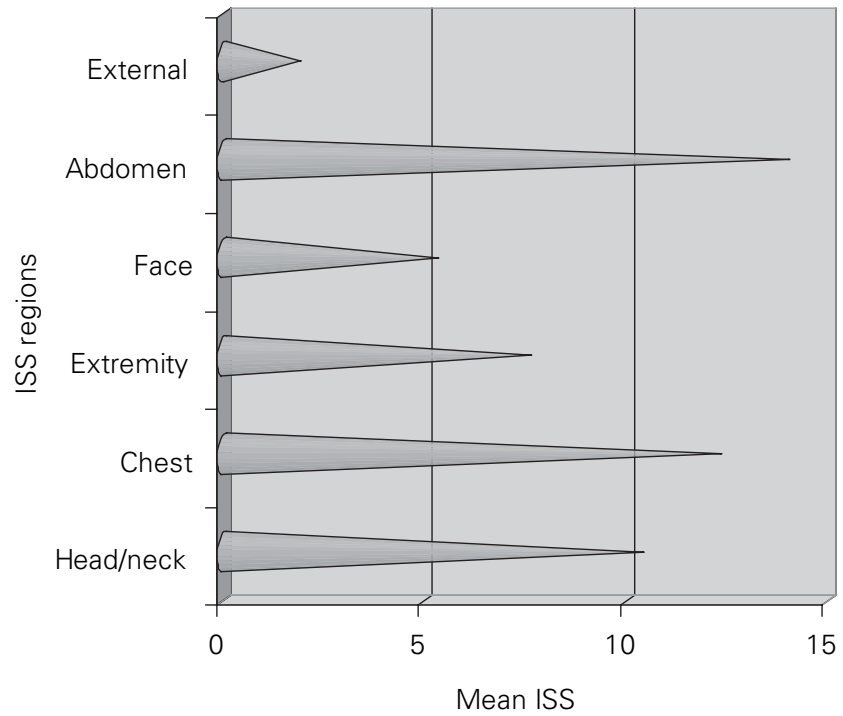

Figure 1. Injury Severity Scores (ISS) for regional injuries.

Extremity injuries included 43 fractures of the tibia and fibula, 34 femoral fractures, 15 humeral fractures, and 16 pelvic fractures. There were 24 fractures of the radius and ulna, five foot and five hand fractures, seven ankle injuries, eight scapular and clavicular fractures, and four joint dislocations. The rest of the injuries $(\mathrm{n}=$ 17) were soft-tissue lesions.

Injuries to the head and neck included 74 unspecified closed head injuries, 18 skull fractures, two intracranial hematomas, and twelve soft-tissue lesions. In the thorax, there were twelve fractures of the ribs with or without associated hemopneumothorax (eight without), two hemothoraces, one pneumothorax, four thoracic spine fractures, and eight soft-tissue lesions.

The specific injuries to the face included six mandibular and maxillofacial fractures, two orbital fractures, and six soft-tissue lesions. In the abdomen, there were two splenic ruptures, one case each of urinary bladder rupture, intraabdominal hemorrhage, liver tear, urethral injury, and lumbar vertebra fracture. There were two anal injuries and two testicular torsions.

\section{Treatment and Outcome}

111 patients $(48 \%)$ were treated nonoperatively while $122(52 \%)$ had surgery. Of those who underwent major surgery $(n=27)$, open reduction and internal fixation of fractures was performed in 17 cases, laparotomies in four, craniotomies in two, arthrodesis in one, and other procedures in three. The commonest minor surgical 
Table 2. Treatment modalities for road traffic injury patients at Kenyatta National Hospital. ORIF: open reduction and internal fixation.

\begin{tabular}{llr}
\hline \multirow{2}{*}{$\begin{array}{l}\text { Treatment modality } \\
\text { Nonoperative }\end{array}$} & \multicolumn{2}{c}{ Patients } \\
\hline Major operation
\end{tabular}

procedure was surgical toilet and debridement with or without wound closure (Table 2).

Overall, the majority of the patients $(34.8 \%)$ had a short hospital stay of 1-2 days. 58 patients stayed for 3-7 days, 28 for 8-14 days, 23 for 15-30 days, and 35 for $>30$ days.

Generally, the length of stay was longer for increasing values of ISS. For injuries of the extremities, however, the longest duration of hospital stay $(19+25$ days $)$ was recorded despite moderate level of ISS. The stay was $9,10,7,13$, and 4 days for head/neck, chest, face, abdomen, and external injuries, respectively.

The overall complication rate was $12.0 \%$ (28 patients). 15 patients died, two developed paraplegia, three had nerve palsies, two had limb amputations, three developed troubling joint stiffness, and one patient each developed hemiparesis, pseudarthrosis and septicemia.

The factors significantly associated with death and disability were an ISS $>15$ and head injury $(\mathrm{p}<0.01)$. Weekend collisions, pedestrian injury and alcohol intake were not significantly associated with bad outcome (Table 3).

15 patients died giving an overall mortality rate of $6.0 \%$. For the subset with major injury, with a mean age of 36 years, mortality rate was $35.6 \%$.

Of the fatalities, nine were pedestrians, three passengers, and two drivers. $93 \%$ of them had associated head injury. Over $70 \%$ of the fatal cases had severe injuries (ISS $>15$ ) with a mean ISS of 21. Most of the fatal collisions $(73.3 \%)$ occurred during the weekend.
Table 3. Factors influencing outcome based on 233 road injury patients seen at Kenyatta National Hospital. ISS: Injury Severity Score.

\begin{tabular}{lccc}
\hline Variable & $\begin{array}{l}\text { Recovery to } \\
\text { discharge } \\
\text { (n) }\end{array}$ & $\begin{array}{l}\text { Death/ } \\
\text { disability } \\
\text { (n) }\end{array}$ & p-value \\
\hline ISS $\leq 15$ & 160 & 6 & $<0.001$ \\
ISS > 15 & 18 & 10 & \\
Alcohol use positive & 83 & 4 & 0.327 \\
No history of alcohol use & 96 & 2 & 0.08 \\
Weekday injury & 98 & 5 & \\
Weekend injury & 92 & 12 & \\
Injury to head/neck & 51 & 12 & 0.001 \\
Injury to other region & 139 & 3 & \\
Pedestrian injured & 117 & 10 & \\
Other road user injured & 68 & 7 & \\
\hline
\end{tabular}

\section{Discussion}

The population studied here represented $31.0 \%$ of all admissions due to injury indicating that a large volume of trauma admissions is handled at this public hospital. Projections using our figures indicate annual admissions of $>3,000$ injury admissions $(13.5 \%$ of these major injury), a volume similar to tertiary trauma facilities in established economies [12] and in keeping with the volume criteria for the designation of trauma centers. Institutional trauma volume is key to optimizing care in these centers whose greatest benefit has been the reduction in trauma mortality [5, 11].

The heterogeneous case mix (mild to critical injury) in this study is of practical significance. Mild to moderate injuries constituted $43.6 \%$ of total while about $12 \%$ sustained injuries of ISS $<2$. This crowding of a tertiary facility with minor injuries reflects the absence of triage before arrival at the KNH. Additionally, it may reflect the nonexistence of trauma admission protocol within our accident and emergency department. Admission of injured patients relies on the perceived trauma acuity by the attending medical officer. Similar patterns of trauma care have been described in Kampala, Uganda [13]. The lack of prehospital triage and the variable case mix of patients also explain the overall moderate acuity (mean ISS 8.78) in this study. The impact of this system is that useful resources including personnel and time are expended on low-acuity patients instead of those with major injury. A coordinated one that includes designated levels of care is desirable. The greatest benefit in terms of mortality is seen in the tertiary levels (level 1 trauma 
centers). This is despite the fact that it is to these centers that patients with major injuries are preferentially transported bypassing lower levels of care.

The average length of hospital stay of 14 days is much longer than in reports from established trauma facilities. At the Vancouver General and Teaching Hospital, Canada, the length in 1997 was 9.14 days despite caring for patients with severer injuries (24\% with ISS > $16)$ than our patients $(13.4 \%$ with ISS $>15)$ [12]. In Germany and Switzerland, lengths of hospital stay of 18-20 days were recorded in 33 hospitals between 1993-1998, but for major injury [14].

The excess length of hospital stay at $\mathrm{KNH}$ is caused by the predominance of skeletal injuries. Long bone fracture fixation is usually performed late, a practice occasioned by the local economic environment and a limiting factor for external validity of this outcome measure. An initial period of nonoperative care, which may last up to 4 weeks, is inevitable. The delay is caused by time spent to raise funds for desired implants. Many patients $(90 \%)$ pay for the services out of their pockets [15]. If a policy of early fracture treatment incorporating a care reimbursement system that does not delay the operative intervention is introduced, the average length of stay may improve. This early fixation would additionally prevent pulmonary failure state, alleviate pain, ease nursing care, reduce complications [16], and allow early rehabilitation and return to work.

The mortality rate of $35 \%$ for patients with severe injury is unexpectedly high for the level of trauma severity reported. In an Italian region for example, mortality was only $24.1 \%$ for a calculated mean ISS of 30 . Further, a quarter of the Italian victims were aged $>69$ years [17]. Although we did not specifically analyze the reasons for the mortality in our series, the high rate seems to mirror that of established economies before the phase of trauma care integration. In some parts of Canada, mortality for major injury was $52 \%$ before trauma care integration. This has now decreased to $18 \%$ [5]. The implication from these studies is that a way out of our current trauma mortality is trauma care regionalization. In San Diego, CA, USA, audit of trauma care before and after implementation of a regional trauma care system [18], showed that improvements in evacuation, disposition and overall trauma care delivery are achieved with implementation. In Victoria, Australia, the preventable trauma death was significantly lower in Melbourne's designated trauma center than in other hospital groups [19]. The mortality in our group of patients was highest for higher ISS and those sustaining head injuries. Studies have shown that the group of patients that benefit most from trauma center care are those with head injuries [5].

This study has several limitations. The wide variation of trauma acuities affected the overall severity, operation rate and outcome and therefore limits comparison with external data. The variable periods of follow-up allowed more complete documentation of complications for patients with long hospital stays. This may underestimate the morbidity in shorter stays.

\section{Conclusion}

RTIs comprised a third of the trauma burden at KNH. The mortality rate for severe injuries was $35.6 \%$ of the cases. This mortality is a function of injury severity and head involvement. The positive attributes of a trauma system in our environment are unlikely to be appreciated until a thorough audit has been undertaken and its recommendations have been implemented. There is need for further studies in this area including the possible contribution of an institutionalized trauma care system.

\section{Acknowledgments}

To the management of KNH for permission to carry out this study. Aspects of the study have been published in abstract forms in the book of abstracts 6th World Injury Congress, Montreal, Canada, May 2002, and the Sicot/Sirot Congress, San Diego, CA, USA, August 2002.

\section{References}

1. Rivara F, Grossman D, Cummings P. Injury prevention: first of two parts. N Engl J Med 1997;337:613-8.

2. Rice D, Mackenzie EA. Cost of injury in the United States: a report to Congress 1989. San Francisco: Institute for Health and Aging, University of California and Injury Prevention Center, The John Hopkins University, 1989.

3. Emenalo S, Pustelli M, Ciampi A, et al. Analysis of road traffic accidents in Zambia. Accid Anal Prev 1977;9:81-91.

4. Hicks A. Mangled or manners: was your accident really necessary? An overall view of road traffic accidents in Kenya. Medicus 1990;9:20-4.

5. Sampalis JS, Denis R, Lavoie A, et al. Trauma care regionalization: a process-outcome evaluation. J Trauma 1999;46:565-81.

6. Smith GS, Barss PG. Unintentional injuries in developing countries: the epidemiology of a neglected problem. Epidemiol Rev 1991;13:226-66.

7. Oluwasanmi AJ. Road accident trends In Nigeria. Accid Anal Prev 1993;25:485-7.

8. Nordberg E. Injuries as a public health problem in Sub-Saharan Africa; epidemiology and prospects for control. East Afr Med J 2000;77:Suppl:S1-43.

9. Odero WO, Kibosia JC. Incidence and characteristics of injuries in Eldoret, Kenya. East Afr Med J 1995;72:706-10. 
10. Saidi HS, Kahoro P. Experience with road traffic accident victims at the Nairobi Hospital. East Afr Med J 2001;78:56-9.

11. Baker SP, O'Neill B, Haddon W, et al. The Injury Severity Score. J Trauma 1974;14:187.

12. Simon R, Eliopoulos V, Laflamme D, et al. Impact on process of trauma care delivery 1 year after the introduction of a trauma program in a provincial trauma center. J Trauma 1999;46:811-6.

13. Kobusingye OC, Guwatudde D, Owor G, et al. Citywide trauma experience in Kampala, Uganda: a call for intervention. Inj Prev 2002;8:133-6.

14. Guenther S, Wydas C, Ose C, et al. Quality of multiple trauma care in 33 German and Swiss trauma centers during a 5 year period; regular versus on-call service. J Trauma 2003;54:973-8.

15. Saidi HS, Ating'a JEO, Macharia W, et al. Risk factor profile and the cost of traffic injury in a tertiary hospital in Kenya. Proceedings of the International Conference on Traffic Safety on Three Continents, Moscow, September, 2001.

16. Gustilo RB, Corpuz V, Sherman RE. Epidemiology, mortality and morbidity in multiple trauma patients. Orthopedics 1985;8: 1523-8.

17. Bartolomeo SD, Sanson G, Michelutto V, et al. Epidemiology of major injury in the population of Friuli Venezia Giulia - Italy. Injury Int J Care Injured 2004;35:391-400.
18. Ornato J, Craren E, Nelsonk N, et al. Impact of improved emergency medical services and emergency trauma care on reduction in mortality from trauma. J Trauma 1985;25:575-9.

19. McDermott FT, Cordner SM, Tremayne AB, and the Consultative Committee on Road Traffic Fatalities. Road traffic fatalities In Victoria, Australia and changes to the trauma care system. Br J Surg 2001;88:1099-104.

\section{Address for Correspondence}

Hassan S. Saidi, B.Sc., M.B.Ch.B, M.Med (Surg)

Department of Human Anatomy

Faculty of Medicine

University of Nairobi

P.O. Box 30197

Nairobi

Kenya

e-mail:hsaid2ke@yahoo.com 